\title{
O LÚDICO NA EDUCAÇÃO A DISTÂNCIA
}

Leonardo de Oliveira Leite*

\section{RESUMO}

O propósito deste trabalho é demonstrar que é possível o desenvolvimento de ambientes virtuais de aprendizagem que propiciem a construção do conhecimento de forma lúdica e interativa.

Estudos realizados apontam a necessidade de criação destes ambientes utilizando estratégias que estimulem a curiosidade, despertem a atenção e desenvolvam as habilidades específicas de observação, associação de idéias e capacidade de análise e síntese dos discentes.

Este trabalho teve como fundamento as atividades finais de conclusão do curso Máster Universitario en Nuevas Tecnologias de la Información y de la Comunicación, realizado no período de 2001 a 2003, na Universidade Nacional de Educación a Distancia (UNED), qual seja a elaboração de Dissertação e a construção de Site com CD-ROM educativo.

Baseou-se também, nas atividades de desenvolvimento e disponibilização de um Sistema de Gerenciamento de Cursos a Distância e dos conteúdos ministrados na disciplina Teoria Geral da Administração, $2^{\circ}$ período, da Faculdade SENAC Minas, a partir do $2^{\circ}$ semestre de 2004.

Palavras-chave: Educação a Distância. Educação Lúdica. Informática Educativa. Lúdico.

Tecnologia Educacional. Ambientes Virtuais de Aprendizagem

\section{INTRODUÇÃO}

Considerando o grande desafio de educar e, principalmente, o de educar a distância, torna-se imperativo que as instituições de ensino, independente de sua natureza, trabalhem em projetos de Educação a Distância (EAD) que visem, num primeiro momento, a mudança de paradigmas e o surgimento de uma nova cultura sobre esta modalidade de ensino.

Para tanto, é necessário rever algumas estratégias de $\mathrm{EAD}$, como a concepção pedagógica dos cursos ou disciplinas, a capacitação dos profissionais envolvidos no processo de construção, principalmente no que se refere as competências exigidas dos mesmos quanto ao desenho, a interface e a interatividade dos programas disponibilizados nas diversas mídias.

Deve-se ressaltar que a aprendizagem aberta, a distância e virtual vislumbra-se como uma estratégia por excelência para enfrentar os desafios da sociedade da informação e do conhecimento. A adoção das tecnologias contemporâneas na educação possibilita uma melhor compreensão das teorias e atividades desenvolvidas no processo de ensino-aprendizagem.

Urge redefinir o ambiente educacional. As tecnologias, principalmente as computacionais, podem ampliar numerosas funções cognitivas humanas: memória (banco de dados), imaginação (simulações), percepção (realidade virtual), raciocínio (inteligência artificial). Por outro lado, as redes telemáticas e os computadores por si só não educam quando abandonamos a interação, a participação, a cooperação entre os agentes cognitivos e a consciência de que o conhecimento é algo a ser construído. "A grande tecnologia é o ser humano, a nossa mente. As tecnologias são extensões da nossa mente, do nosso corpo". (MORAN, 1966).

Assim, o projeto pedagógico proposto para a construção de ambientes virtuais de aprendizagem deve-se fundamentar nos princípios do construtivismo. Neste caso, a premissa

\footnotetext{
* Professor Especialista da Faculdade SENAC-MG

Master em Novas Tecnologias da Informação e Comunicação - UNED-ES

Especialista em Educação a Distância - PUC Minas Virtual

Analista de Sistemas de Informação

Bacharel em Administração de Empresas

leonardo@uemg.br / lleite@terra.es / leonardol@pbh.mg.senac.br
} 
básica é que o indivíduo é agente ativo de seu próprio conhecimento. O processo de formação tem como eixo fundamental a atividade consciente e intencional do aluno na resolução de problemas do mundo real, valendo-se das diversas competências existentes e/ou adquiridas, permitindo assim, a formação de uma consciência reflexiva sobre sua aprendizagem. Isto se justifica uma vez que ele constrói significados e define o seu próprio sentido e representação da realidade de acordo com suas experiências e vivências em diferentes contextos.

Contudo, o maior desafio é desenvolver ambientes virtuais de aprendizagem que contemplem estas competências, não apenas por questões técnicas, mas principalmente culturais, uma vez que estamos habituados ao modelo tradicional de transmissão do conhecimento em nossa própria prática como professores e aprendizes.

As possibilidades de interação, proporcionadas pelas Tecnologias da Informação e Comunicação (TIC's), têm despertado o interesse de muitas instituições. Contudo, pode-se perceber que os cursos ofertados estão estruturados, basicamente, em forma de textos e imagens fixas e não fogem ao padrão: chat, fórum, e-mail, bloco de notas.

Por outro lado, pode-se encontrar no mercado uma infinidade de softwares capazes de criar um ambiente de aprendizagem mais reflexivo, atraente, inteligente e por que não dizer lúdico!

Navegando na Internet é possível encontrar diversas animações na forma de charges ou joguinhos, alguns de excelente qualidade; contudo, a utilização desses recursos ainda é pouco expressiva no meio educacional, principalmente na EAD, em cursos para jovens e adultos.

Diante deste cenário, procurou-se trabalhar na construção de um ambiente virtual de aprendizagem que, em conjunto com a modalidade presencial, pudesse oferecer aos discentes uma outra alternativa de ensino-aprendizagem, buscando elevar seu nível de conhecimento e informação e, ao mesmo tempo, proporcionar-Ihes a inclusão digital familiarizando com esta modalidade de ensino.

Parte-se do pressuposto de que as novas demandas de informação e de comunicação incidem na relação ensino-aprendizagem e que os meios de comunicação estão, a cada dia mais, revolucionando as formas de obtenção da informação. Além disso, não se deve omitir que esta nova geração é apontada como digital. Todo um ferramental tecnológico está sendo produzido para este segmento de mercado, nas mais diversas faixas etárias. Os jogos eletrônicos, interativos, em rede, os simuladores e muitos outros contribuem para o desenvolvimento das inteligências múltiplas propostas por Gardner e, paralelamente, exige uma reformulação do processo de educação baseado na transmissão expositiva de informações.

\section{EDUCAÇÃO LÚDICA}

Etimologicamente, o termo lúdico é derivado de ludus que no latim está associado às brincadeiras, aos jogos de regras, à recreação, ao teatro, às competições, sendo assim, o que possui maior abrangência. Com ênfase ao trabalho pedagógico de valorizar o "jogar", explorando a ludicidade das atividades, surge a expressão "Educação Lúdica".

A Educação Lúdica visa estudar e valorizar um novo processo de desenvolvimento da capacidade física, intelectual e moral do ser humano por meio do uso de brinquedos, jogos e materiais didáticos coligados que sirvam de suporte para que o sujeito da aprendizagem aprenda de forma mais descontraída, efetiva, eficiente e eficaz.

Desde a antiguidade, o brinquedo se tornou um meio, um instrumento para potencializar a aprendizagem. Aristóteles já relacionava o estudo ao prazer e os professores de sua época já utilizavam os "jogos didáticos" no estudo da matemática, filosofia, dentre outros. Da mesma forma, ao classificar os vários aspectos do homem, Aristóteles dividiu-os em homo sapiens (homem que conhece e aprende), homo faber (o que faz e produz) e homo ludens (o que brinca, o que cria)

Acredita-se na importância e no auxílio do lúdico como estratégia básica do professor que busca trabalhar conteúdo, de forma prazerosa e eficaz com seus discentes.

Piaget, preocupado em explicar os processos internos a partir dos quais o indivíduo adquire conhecimento, afirma que "a função da atividade lúdica ou simbólica é dar um outro valor aos objetos criando uma realidade diferenciada, adequando-os ao seu mundo (o mundo da fantasia). A imitação (baseada na acomodação) e o jogo (baseado na assimilação da realidade ao pensamento privado e egocêntrico) representam os extremos de duas funções, que devem atuar juntas para se atingir o equilíbrio".

$\mathrm{Na}$ atividade lúdica, o objeto representa um símbolo que sugere algo pré-existente na mente do aprendiz. Por meio dela é possível reproduzir a realidade, às vezes escondida e tão almejada pelos docentes. 
Da mesma forma, Vygotsky ao investigar o desenvolvimento do conhecimento nas crianças relatou que "ao brincar com um tijolinho de madeira como se fosse um carrinho, por exemplo, ela se relaciona com o significado em questão (a idéia do carro) e não com o objeto concreto que tem nas mãos. O tijolinho de madeira serve como uma representação de uma realidade ausente e ajuda a criança a separar objeto-significado". Com o brinquedo, a criança começa a construir seu mundo real, através de situações imaginárias. Porém, ao se deparar com um objeto, ela é capaz de dar significados próprios, independente do que ela está vendo. Assim, começa a agir de forma independente, e aquele objeto perde sua força determinadora, dando lugar à posição formada da criança em relação às determinadas situações e à própria realidade. Defende a idéia de que o jogo infantil não é simplesmente uma recordação do que já foi vivido. É todo um processo criativo das impressões vividas, suas combinações e construções. Uma nova realidade será apresentada a cada momento e essa criação é de autoria da criança.

Surge um novo paradigma do jogo que abandona sua relação com a futilidade para se tornar uma educação natural.

O ser humano (em especial, o adulto) aprende mais e melhor quando é exposto a diferentes estímulos no processo de assimilação de conhecimento.

Para Paulo Freire, "a educação é comunicação, é diálogo, na medida em que não é transferência de saber, mas um encontro de sujeitos interlocutores que buscam a significação dos significados".

Nas palavras de MORIN (apud GITAHY, 2003) as "trocas entre o real e o imaginário, nas sociedades modernas, se efetuam no modo estético, através das artes, dos espetáculos, dos romances, das obras ditas de imaginação". Portanto, diferentes mídias podem ser integradas, não apenas em seu apelo visual, mas em decisões de ensino que possam potencializar uma efetividade maior ao processo educativo.

APARICI (et alli) afirma que na vida diária os estímulos não se apresentam de maneira isolada, mas de forma conjunta. A percepção de um objeto ou de um trecho é determinada não só por uma série de estímulos externos, mas também por nossas necessidades, motivações, atitudes, valores, assim como pelo contexto sociocultural na qual o sujeito está inserido.

As percepções são provenientes de dois fatores: objetivos e subjetivos. Dentre os objetivos destacam-se o visual que responde por $40 \%$, o auditivo - 30\%, o tátil - $15 \%$, o olfato $-10 \%$ e o paladar que representa $5 \%$. Estas porcentagens indicam a proporção de influência que estes fatores exercem na aprendizagem.

Vale ressaltar que o lúdico, aqui proposto, não se refere apenas a jogos ou brincadeiras, mas à utilização eficiente e eficaz dos recursos computacionais disponíveis de forma que possam retratar, mediante animações interativas ou não, a história da humanidade com maior entendimento e clareza aos discentes.

\section{HOMO VIRTUAL}

MORIN (1975) apresenta o ser social como produto de seu século reunindo em si três espécies de gêneros o Homo sapiens, Demens e Virtual. Estas espécies são caracterizadas da seguinte forma:

Homo sapiens - ser racional, vive um dilema, uma angústia que está relacionada com a sua imortalidade. "... a morte se torna um problema vivo, isto é, que afeta a sua vida";

Homo Demens - fruto da cultura de massa tradicional, mantém um relacionamento estreito com o real e o imaginário por meio do espetáculo, da estética. Busca, também, "a imortalidade, vivencia o mito da ideologia do progresso";

Homo Virtual - encontrado na cultura de massa ciber, espaço este criado por ele, simula o mundo real por meio das mídias digitais, em especial as multimídias interativas ou realidade virtual.

LÉVY (1996) afirma que "o virtual usa novos espaços e novas velocidades, sempre problematizando e reinventando o mundo. Outro caráter que confere à virtualidade é o de sua passagem do interior ao exterior e do exterior ao interior".

COSTA (apud GITAHY) apresenta o perfil do Homo Virtual. Merecem destaque: "tem sentimento pelo seu computador humanizado; tem novos modos de perceber o mundo ao seu redor e as suas próprias experiências nele; as experiências do novo homem no ciberespaço produziram novas formas de pensar; cria novos usos de linguagem; tem que lidar com novos conflitos internos, novas fontes de ansiedade e novos medos de enlouquecer frente a realidades diferentes: a real e a virtual". 
$\mathrm{Na}$ atualidade, o computador se torna parte do desenvolvimento da personalidade, da identidade e do intelecto das novas gerações. TURKLE (apud GITAHY) afirma que "para adultos e para crianças que brincam com jogos de computador, que usam o computador para manipular palavras, informações, imagens visuais e especialmente para aqueles que aprendem a programar, os computadores entram no desenvolvimento da personalidade, da identidade e mesmo da sexualidade". E complementa "(...) numa variante da estória de Narciso, as pessoas podem cair de amores pelos mundos artificiais que construíram ou que foram construídos para elas por outras. As pessoas são capazes de se verem no computador" .

Para MORIN (1991) esta tecnologia permite desenvolver pensamentos complexos, pois reforça e desenvolve "a autonomia pensante e a reflexão consciente dos indivíduos".

Não poderiam passar desapercebidas as palavras de IANNI (1999): "tudo se globaliza e virtualiza, como se as coisas, as gentes e as idéias se transfigurassem pela magia da eletrônica. A onda modernizante não pára nunca, espalhando-se pelos mais remotos e recônditos cantos e recantos dos modos de vida e trabalho, das relações sociais, das objetividades, subjetividades, imaginários e afetividade".

Vale destacar o relatório da Organização das Nações Unidas para a Educação, a Ciência e a Cultura (UNESCO) sobre a Educação para o século XXI. A nova educação no mundo contemporâneo deve estar assentada em quatro pilares: Aprender a Conhecer; Aprender a Fazer; Aprender a Conviver; Aprender a Ser.

$\mathrm{Na}$ perspectiva da visão tecnológica os pilares podem assim ser descritos: "Aprender a Conhecer" está associado às fontes de informação e aos novos meios de acesso a elas; "Aprender a fazer" enfatiza a mobilização e desenvolvimento de competências de forma que o sujeito possa se adaptar a um novo contexto de trabalho, de natureza intelectual exigindo uma sólida base tecnológica; "Aprender a conviver" tem consigo a noção de interação, a construção de comunidades virtuais de aprendizagem colaborativa; "Aprender ser" no mundo virtual ainda é um pouco complicado, questões como ética, direitos autorais ou propriedade intelectual devem ser trabalhados tanto com os discentes quanto com os docentes. Os famosos "CTRL + A" mais "CTRL + C" e "CTRL + V" e os diversos sites que disponibilizam trabalhos e conteúdos gratuitamente ou não, ainda serão um grande desafio a vencer.

\section{AMBIENTE VIRTUAL DE APRENDIZAGEM}

Dentro dos pressupostos do "aprender fazendo" e a "construção do conhecimento" as mídias a serem utilizadas em cursos de EAD devem oferecer aos aprendizes condições de interagir em todos os sentidos, seja consigo mesmo (reflexão crítica a partir de suas experiências e do próprio conhecimento sobre o assunto) ou com terceiros.

Da mesma forma, a organização dos conteúdos a serem disponibilizados na Web deve apresentar um desenho que estimule a curiosidade do discente, que prenda sua atenção, desenvolva as habilidades de observação, associação de idéias e análise de acordo com sua realidade para interpretá-la e, consequentemente, re-construir o conhecimento.

Em teoria, quanto mais dialógica for a interface do sistema melhor serão os níveis de interação em cursos de EAD. O ponto mais crítico é desenvolver cursos que estabeleçam um envolvimento mental do discente com os conteúdos.

Vale ressaltar que o material disponibilizado deve possibilitar que o discente concretize sua autonomia, por meio de ações investigativas e críticas, frente aos conteúdos que lhes são apresentados. ABREU (apud BARROS) afirma que um "software deve viabilizar trocas funcionais entre o aluno e o programa, (...): não fornecer o conteúdo diretamente ao aluno, enfatizar a descoberta, a atividade, a exploração, compreender o erro como etapa do processo de pensar (...), considerar o papel do professor como facilitador da aprendizagem, entre outras".

LITTO (2003) afirma que "existe a pobreza dos ambientes virtuais de aprendizado: quem procura um curso não presencial quer interatividade, quer se sentir desafiado. É preciso que os organizadores dos cursos pensem em criar objetos de aprendizado estimulantes, como animações, simulações, formas que façam o aluno a entender a concretização daquele conhecimento"

BIROCCHI (2003) complementa, "o importante é estimular o aluno de forma permanente. Nas aulas, é essencial oferecer formas de interatividade dinâmica, animações bem feitas, simulações instigantes". 
TURROFF (1995) comenta que "embora muitas pessoas percebam que o uso das tecnologias seja implicitamente inovador, 0 uso da tecnologia na aprendizagem a distância tem freqüentemente repetido os mais ineficazes métodos de instrução ao vivo, face a face".

LITTO (Ibid) acrescenta "se o educador tenta transpor suas técnicas de sala de aula para o ambiente virtual, pode facilmente entediar seus alunos e assistir a uma grande evasão em seus cursos". Nesse sentido, os profissionais envolvidos na construção de cursos a distância devem ser mais que arquitetos do conhecimento.

Há, portanto, a necessidade de uma equipe interdisciplinar para a construção de conteúdos virtuais. Esta, atuante nas diversas áreas do conhecimento, deve ter um perfil generalistaespecialista, e habilidades em Teorias da Aprendizagem, Tecnologia Educacional e conhecimento específico do conteúdo a ser trabalhado.

POPPOVIC (1996) relata que os resultados das pesquisas sobre a atitude dos professores em relação a novas tecnologias educacionais apresentam-se numa curva normal. "À direita, há cerca de $7 \%$ a $10 \%$ de professores altamente motivados para a incorporação da tecnologia. Destes, boa parte possui um computador em casa; todos são favoráveis ao 'novo'. À esquerda da curva, verifica-se que cerca de $15 \%$ são 'fóbicos' no que se refere à tecnologia. Eles 'odeiam' computadores e racionalizam seu medo de inovações usando toda sorte de argumentos. Entre esses pólos, a grande maioria dos professores está num continuum. Representam aproximadamente $75 \%$ do professorado".

NEGROPONTE (1999) aponta um bom contra argumento às críticas ao uso das TIC's "tenha em mente que a tecnofobia não é injustificável: os micros estão cada vez mais complexos e o uso deles tem se tornado uma situação cada vez mais humilhante (...). O tecnofóbico precisa sentir, antes de tudo, que a nova habilidade é uma questão de vida, não de computadores" .

Diante desse cenário, a formação e as práticas dos profissionais em educação vêm forçandoos a tomarem novas posturas. PETTERS (2003) ressalta que trata de um grupo relativamente homogêneo de interessados, contudo, "(...) indivíduos muitas vezes bem diferentes, de exigências intelectuais distintas e com respectivos objetivos especiais, como seria de se esperar de estudantes em idade adulta, média ou mais avançada. O desenvolvimento dessas versões de hipertextos e hipermídias do ensino é uma tarefa difícil para os docentes(...)" e argumenta que estas competências são exclusivas de especialistas da área tecnológica. Portanto, há a necessidade que o docente adquirira uma cultura tecnológica, para desdramatizar o temor da perda do controle do professor educativo para os informáticos.

Deve-se considerar que o objetivo do Programa: Escola moderna é o de contribuir para a melhoria da qualidade do ensino, em todos os seus níveis e modalidades, por meio da oferta de práticas pedagógicas modernas, materiais didáticos atualizados, inovação tecnológica e infra-estrutura física e instrumental necessários à aprendizagem.

\section{O CASTOR VIRTUAL}

Ser, no mundo virtual, um construtor ou engenheiro ou arquiteto exige do profissional habilidades que, para o mundo real, são um tanto enigmáticas, dentre elas destacam-se a capacidade de construir roteiros, storyboard, mapas de navegação, a interface e interatividade que constituem elementos fundamentais para que o desenvolvimento de uma aplicação lúdica em EAD ocorra da melhor forma possível.

$\mathrm{Na}$ construção do roteiro o profissional deverá desenvolver todos os conteúdos específicos de cada bloco temático. Junto a eles, deve-se especificar as diversas mídias e linguagens que irá utilizar no desenvolvimento do mesmo. Deve-se pensar nas imagens, sons, animações, textos. Para que haja uma integração adequada entre as diferentes linguagens, é necessário distribuir os conteúdos de acordo com as mídias que irão incorporá-los. É de suma importância que se tenha um conhecimento geral de todas as possibilidades de transmissão do conhecimento, seja na forma textual, imagens, sons, filmes, animações etc.

O Storyboard, considerado como Guia Técnico, é muito utilizado na produção de filmes e animações. Trata-se na realidade de um roteiro em quadrinhos, onde o arquiteto deverá descrever a visualização dos conteúdos e sua disposição nas respectivas telas. Requer do profissional habilidades em planos ou enquadramento, perspectivas. Ele deverá trabalhar o layout de cada tela.

O Mapa de Navegação é o esboço das conexões ou vínculos entre as diversas telas da aplicação. Este desenho informa como se acessa de um determinado lugar para o outro. Existem quatro estruturas de navegação: a linear; hierárquica, a não linear e a composta. 
Deve-se ressaltar que é de suma importância que o usuário tenha a sensação de poder navegar livremente sem se perder.

É por meio da interface que as pessoas estabelecem uma comunicação com os programas sendo considerada uma das partes mais importantes da aplicação. Para que seja amigável é importante que não oponha nenhuma resistência ou dificuldade durante a navegação. Alguns requisitos mínimos são exigidos como: deve ter uma concepção uniforme entre todas as telas; os botões devem executar ações comuns; em qualquer momento da navegação deve-se ter a possibilidade de ir a qualquer lugar ou sair da aplicação.

Dentro do contexto de comunicação mediada por computador, do contexto da EAD, da engenharia de software e de todas as áreas que lidam com a interação homem-máquina e homem-homem via computador, encontra-se o conceito de interatividade. Um termo tão importante que, segundo alguns autores, o uso indiscriminado vem causando a banalização do mesmo. Trata-se de uma ação dialógica entre o homem e a técnica. Contudo deve-se considerar que existem níveis de interação que influenciam na qualidade da aplicação.

Segundo ACEDO (2000) a interavidade não é uma imitação de gestos ou ações, é a participação ativa que levam a decisões por parte do usuário. Para tanto, deve-se evitar períodos longos em que o usuário não interage com a mídia. Ela as divide em cinco níveis:

1ำ Nível de Interatividade: o meio apresenta informações na forma visual, sonora e textual e o usuário tem de escolher entre as diversas opções sem ter outra alternativa. O programa multimídia informa ao usuário e este só pode seguir o itinerário ou os itinerários prefixados pelo programador.

2ํNível de Interatividade: o programa multimídia pergunta e avalia o usuário quantitativamente. O meio impõe o ritmo da apresentação das informações e a opções de escolha do usuário são muito limitadas.

3ํNível de Interatividade: o meio detecta carências, analisa a repetição de erros e os temas não estudados pelo usuário. O usuário tem a possibilidade de escolher seu próprio itinerário. Assim, o programa multimídia apresenta as opções e adapta-se a oferta de demanda do usuário.

4ํNível de Interatividade: este nível de interatividade permite ao usuário tomar a iniciativa e consultar o meio através do teclado ou outro dispositivo de entrada. A multimídia realiza uma resposta adaptada conforme as dúvidas do usuário. São programas multimídias abertos tipo Programas de Ajuda, Enciclopédias, entre outros.

5 Nível de Interatividade: corresponde a um grau superior de interatividade. Sem dúvida, este quinto nível é um nível fictício. A título de exemplos pode-se citar os Programas de Autoria, os Programas de Apresentação e Linguagem de Programas, que não são na realidade, programas multimídia senão ferramentas para a realização multimídia.

\section{CONSIDERAÇÕES FINAIS}

Este trabalho está sendo aplicado na Faculdade SENAC Minas, curso Administração de Empresas: Habilitação Administração Hoteleira, disciplina Teoria Geral da Administração, $2^{\circ}$ período.

Para o desenvolvimento do ambiente virtual de aprendizagem optou-se por trabalhar com a linguagem de programação PHP, MySQL como banco de dados e o Flash MX para a criação das animações.

As atividades tiveram início em agosto de 2004 foram suspensas na segunda quinzena de dezembro, término do período letivo. Deve-se deixar registrado que trata-se de um projeto piloto e muitas adequações ainda devem ser realizadas.

As atividades, desenvolvimento do ambiente e aula presencial, ocorriam concomitantemente. Portanto, deu-se maior ênfase na construção dos seguintes espaços: Aulas, Anotações, Glossário, Contato, Biblioteca, Respostas (FAQ dinâmico) e o Debate (Fórum).

143 discentes participaram deste projeto piloto, sendo que o número de usuários cadastrados no ambiente foi de 60, destes, 4 eram considerados anônimos, isto em função de existir discentes que não possuem computador e, principalmente, condições de acesso à Internet. Vale registrar que a Faculdade viabilizou a estes o acesso a Internet por intermédio do laboratório de informática.

O número total de acessos registrados no período foi de 3914 , sendo que o maior índice ocorria nos finais de semanas, e nos dias úteis à noite, com maior freqüência.

Logo de início, percebeu-se que a maioria dos discentes não está familiarizada com este tipo de ambiente de aprendizagem. 
Como estratégia, disponibilizou-se os conteúdos de acordo com a evolução do planejamento. Assim, o aluno teria acesso a todo o conteúdo estudado, tornando a ferramenta uma espécie de "monitor".

O desenvolvimento do trabalho ocorreu em três etapas, não definidas no planejamento mas no decorrer do processo. Houve, num primeiro momento, um alto índice de acessos. Os discentes baixavam os conteúdos das aulas, e muitos se limitavam a esta ação, deixando de explorar os demais recursos existentes.

Após a primeira avaliação, o processo se alterou. Os alunos que exploravam as aulas virtuais fizeram todas as atividades propostas com bom aproveitamento. Em sala de aula, alguns deles demonstravam que a ferramenta era eficiente recurso para a sua aprendizagem, e mais, a maioria dos alunos passou a estudar só com a sua utilização, intensificando a interação com o professor por meio do espaço CONTATO.

No entanto, percebeu-se que a ferramenta fez com que o acesso ao acervo da Biblioteca da Faculdade reduzisse na disciplina Teoria Geral da Administração. A estratégia teve que ser revista em função desta ocorrência.

Os discentes se organizavam em grupos presenciais trabalhando os conteúdos das aulas virtuais. Acredita-se que em função desta proximidade o espaço RESPOSTA foi pouco utilizado. Quanto ao espaço DEBATE, a disponibilização do mesmo só ocorreu em meados de outubro, tendo em vista o acúmulo de atividades das outras disciplinas do currículo optou-se pela sua utilização no 1ำ semestre de 2005.

No final de novembro o acesso ao sistema foi restrito aos espaços GLOSSÁRIO, BIBLIOTECA e CONTATO. A sala de aula foi desativada com o intuito de possibilitar o aprofundamento de leituras da bibliografia básica e complementar.

$\mathrm{Na}$ última etapa, houve uma grande mobilização por parte dos discentes para o acesso à SALA DE AULA.

Percebeu-se que utilizar animações, ilustrando situações que exigiam maior grau de abstração, contribuiu para a fixação e assimilação dos conteúdos trabalhados. Eram freqüentes comentários do tipo: "é muito tranqüilo aprender depois de ver a animação"; "a gente fixa melhor o conteúdo trabalhado em sala de aula quando assiste à aula virtual"; "só com a aula presencial e a virtual assimilei o conteúdo trabalhado".

Este trabalho continua em construção. No ano de 2005, ele deverá ser aprimorado oferecendo aos discentes outros espaços virtuais. Contudo fica evidente que a ludicidade contribui, em muito, para melhoria da qualidade do ensino e da aprendizagem.

Pretende-se com ele oferecer uma oportunidade de interlocução com todos aqueles que acreditam na EAD, em especial na a Educação Lúdica Virtual.

\section{BIBLIOGRAFIA}

ACEDO, Sara Osuna. Multimídia: Entornos Virtuales e Interactivos. Universidad Nacional de Educación a Distancia. 2000.

APARICI, Roberto. GARCÍA MATILLA, Agustín. VALDIVIA SANTIAGO, Manuel. La Imagem. Madrid, 2000.

BARROS, Edlaine Fátima de. Software Educacional: Critérios a serem levados em conta no processo pedagógico. Revista Brasileira de Tecnologia Educacional - Anos XXX/XXXI, no 159/160, 2003.

BIROCCHI, René. A trajetória do ensino remoto. Revista Galileu, Ano 12, n. 142, Maio-2003.

BROUGÈRE, Gilles. Jogo e educação. Ed. Artes Médicas.Porto. Alegre:1998.

GITAHY, Raquel Rosan Christino; Menin, Maria Suzana de Stefano. A Educação na Era da Tecnologia: $O$ aluno como ser virtual. Revista Brasileira de Tecnologia Educacional - Anos XXX/XXXI, no 159/160, 2003.

IANNI, Octavio. Teorias da Globalização. 5ª ed. Rio de Janeiro: Civilizações Brasileira, 1999.

LÈVY, Pierre. O que é virtual? Tradução Paulo Neves, São Paulo: Editora 34, 1996. 
LITTO, Fredric. Pedagogia sob medida. Revista Galileu, Ano 12, n. 142, Maio-2003.

NEGROPONTE, Nicholas. Comunicação sem fio, shopping e tecnofobia. Folha de São Paulo, São Paulo, 3 fev. 1999, Caderno de Informática, p2.

PETERS, Otto. Didática do ensino a distância. São Leopoldo, RS: Editora Unisinos, 2001.

POPPOVIC, Pedro Paulo. Educação à distância: problemas da incorporação de tecnologias educacionais modernas nos países em desenvolvimento. Em Aberto, v.16, n.70, 1996. 